\title{
PELATIHAN PRODUKSI DAN USAHA COOKIES BERBAHAN BAKU LOKAL SEBAGAI ALTERATIF USAHA BAGI MANTAN TKI (TENAGA KERJA INDONESIA) DI DESA SINDANGSARI KECAMATAN CIKAUM KABUPATEN SUBANG
}

\author{
Tarma, Uswatun Hasanah, Mulyati \\ Program Studi Pendidikan Kesejahteraan Keluarga \\ Fakultas Teknik Universitas Negeri Jakarta
}

\begin{abstract}
ABSTRAK
Provinsi Jawa Barat merupakan provinsi lumbung tenaga kerja Indonesia yang bekerja di luar negeri. Di Provinsi Jawa Barat, Kabupaten Subang merupakan salah satu kabupaten yang menyumbang tenaga kerja Indonesia yang bekerja di luar negeri dengan jumlah yang besar. Secara nasional perkabupaten, Kabupaten Subang menempati urutan ke-11 penyumbang jumlah TKI yang bekerja di luar negeri. Berdasarkan sektor pekerjaanya, TKI asal Subang umumnya bekerja di sektor informal sebagai asisten rumah tangga. Banyak permasalahan yang dihadapi oleh TKI selama bekerja di luar negeri seperti kekerasan fisik, keterlambatan gaji, gaji tidak dibayar dan PHK sepihak, bahkan sampai ada yang meninggal dunia. Sepulangnya dari bekerja sebagai TKI di negara lain, kehidupan mantan TKI adakalanya tidak membaik, bahkan tidak sedikit yang kembali ke kehidupan semula dengan kondisi ekonomi yang tidak lebih baik. Sehingga tidak sedikit yang kembali menjadi TKI. Pada umumnya mereka kembali menjadi TKI karena tidak memiliki keterampilan yang dapat diandalkan untuk bekerja atau menyadi sirausaha di dalam negeri. Untuk itu, kami memandang penting untuk melakukan pengabdian masyarakat yang berjudul "Pelatihan Produksi dan Usaha Cookies Berbahan Baku Lokal Sebagai Alteratif Usaha Bagi Mantan TKI (Tenaga Kerja Indonesia) di Desa Sindangsari Kecamatan Cikaum Kabupaten Subang”

Kegiatan pengabdian masyarakat ini telah dilaksanakan pada tanggal 28 Agustus 2016 bertempat di kompleks madrasah Masjid Aminah Binti Wahab, Dusun Krajan Utara Desa Sindangsari, Kecamatan Cikaum, Kabupaten Subang. Kegiatan diikuti oleh 22 orang peserta ibu-ibu mantan tenaga kerja Indonesia (TKI) yang di antaranya pernah bekerja di Abudabi, Saudi Arabia, Singapura, Taiwan dan Malaysia. Kegiatan pelatihan berjalan dengan lancar dan peserta mendapatkan pengetahuan dan keterampilan sesuai target yang ditetapkan.
\end{abstract}

Kata Kunci: cookies, bahan baku lokal, mengelola usaha

\section{PENDAHULUAN}

Jawa Barat merupakan provinsi dengan penymbang terbanyak tenaga kerja indonesia (TKI) yang bekerja di luar negeri yakni sebanyak 105.476 orang. Berdasarkan peringkat kabupaten, Subang menempati peringkat ke-11 dengan 8.357 orang warganya menjadi TKI di luar negeri. ${ }^{1}$ Jumlah tersebut merupakan gambaran bahwa kondisi di dalam negeri dalam perspektif TKI tidak menjanjikan, sehingga mereka lebih memilih bekerja di luar negeri. Berdasarkan negara tujuan, Taiwan merupakan negara tujuan yang paling diminati. Sementara daerah tujuan lainnya ialah Bahrain, Brunei Darussalam,
Hongkong, Malaysia, Oman, Qatar, Saudi Arabia, Singapura, dan Uni Emirat Arab. Berdasarkan jenis pekerjaannya, umumnya warga Subang yang menjadi TKI bekerja di sektor informal sebagai pembantu rumah tangga, sementara sisanya bekerja sebagai buruh pabrik. ${ }^{2}$

Sebagia mereka ada yang bernasib mujur sehingga sekembalinya dari negara lain dapat mengumpulkan kekayaan untuk melanjutkan hidup dengan lebih baik di Indonesia. Sebagian lainnya lebih memilih untuk bolak-balik kembali menjadi TKI setelah beberapa kali kembali ke tanah air. Sementara sebagian lagi ada yang tidak ingin kembali menjadi TKI. 
Nyatanya ada pula cerita pilu yang dialami oleh TKI asal Kabupaten Subang. Pertanggal 10 September 2015, sebanyak 68 TKI asal subang tersangkut masalah. Permasalahan tersebut di antaranua ialah mengalami kekerasan fisik, gaji tidak dibayar penuh, dan PHK sepihak. Kisah pilu di antaranya dialami oleh Ijah yang ditusuk oleh majikannya gara-gara telat menyetrika baju dan tidak mengerti bahasa majikan saat memerintahnya. ${ }^{3}$ Kisah lebih tragis dialami oleh Warsinah Binti Ahmad Wasid yang meninggal akibat kecelakaan lalu lintas. Gaji Warsinah yang seharusnya dibayarkan 24 juta, hanya diberikan 18 juta. ${ }^{4}$ Kondisi menyedihkan lainnya dialami oleh Sumirah Binti Soma yang meninggal setelah pulang dari Bahrain dengankondisi luka di bagian kepala dan kaki akibat kecelakaan di rumah majikannya. ${ }^{5}$

Dengan berbagai kondisi memprihatinkan tersebut, alangkah baiknya bila TKI asal Subang yang sudah kembali ke tanah air tidak berniat untuk kembali bekerja sebagai TKI di negara lain. Dengan berbagai resiko berat yang akan dihadapi, semestinya calon TKI berpikri ulang untuk memutuskan bekerja menjadi TKI. Namun permasalahan yang terjadi ialah sepulangnya dari luar negeri, para mantan TKI tidak memiliki keterampilan yang dapat diandalkan untuk berwirausaha. Sehingga penghasilan yang didapatkan selama menjadi TKI habis digunakan untuk kebutuhan konsumtif.

Untuk membuat para mantan TKI tidak kembali bekerja di luar negeri, diperlukan pengembangan keterampilan teknis untuk dapat berwirausaha. Salah satu jenis usaha yang tidak pernah sepi dan menjanjikan ialah di sektor makanan. Di antara usaha sektor makanan yang berpeluang untuk dikembangkan ialah kue kering atau cookies. Atas dasar itu, dalam pengabdian masyarakat ini kami melaksanakan: "Pelatihan Produksi dan Usaha Cookies Berbahan Baku Lokal Sebagai Alteratif Usaha Bagi Mantan TKI (Tenaga Kerja Indonesia) di Desa Sindangsari Kecamatan Cikaum Kabupaten Subang". Wilayah Desa Sindangsari Kecamatan Cikaum dipilih karena di desa dan/atau kecamatan ini banyak warganya yang bekerja di luar negeri sebagai TKI.

Berdasarkan pada analisis situasi di atas, permasalahan yang terjadi Kecamatan Cikaum Kabupaten Subang yang dirumuskan yaitu belum adanya alternatif usahan bagi mantan TKI. Kemudian pertanyaan yang diajukan sebagai basis pengabdian masyarakat ini ialah: "Bagaimana dampak pelatihan Pelatihan Produksi dan Usaha Cookies Berbahan Baku Lokal Sebagai Alteratif Usaha Bagi Mantan TKI (Tenaga Kerja Indonesia) di Desa Sindangsari Kecamatan Cikaum Kabupaten Subang?"

Sasaran dari kegiatan Pelatihan Produksi dan Usaha Cookies Berbahan Baku Lokal Sebagai Alteratif Usaha Bagi Mantan TKI (Tenaga Kerja Indonesia) di Desa Sindangsari Kecamatan Cikaum Kabupaten Subang adalah 20 orang mantan TKI. Adapun target yang hendak dicapai yaitu: (1) peserta memiliki pengetahuan yang memadai tentang peluang usaha dari produksi cookies berbahan baku lokal; (2) peserta memiliki keterampilan pembuatan cookies dengan memanfaatkan bahan baku lokal setempat; (3) peserta memilki keterampilan pengemasan cookies sehingga hasil produksi menarik bagi konsumen; dan (4) peserta memiliki kemampuan mengelola usaha cookies sebagai salah satu alternatif mata pencaharian. Setelah pelaksanaan Pelatihan Produksi dan Usaha Cookies Berbahan Baku Lokal Sebagai Alteratif Usaha Bagi Mantan TKI (Tenaga Kerja Indonesia) di Desa Sindangsari Kecamatan Cikaum Kabupaten Subang ini, luaran yang diharapkan yaitu: (1) produk cookies berbahan baku lokal yang dapat dipasarkan; dan (2) keterampilan dalam membuat cookies dan mengelola usaha cookies berbahan baku lokal.

\section{METODE KEGIATAN}

Tujuan dari Pelatihan Produksi dan Usaha Cookies Berbahan Baku Lokal Sebagai Alteratif Usaha Bagi Mantan TKI (Tenaga Kerja

\footnotetext{
${ }^{1}$ http://www.bnp2tki.go.id/readfull/9801/Sepanjang-2014-BNP2TKI-Mencatat-Penempatan-TKI-429.872-Orang ${ }^{2}$ http://targetabloid.co.id/berita/4420-lebih-dari-2700-warga-subang-jadi-tki-diluar-negeri

${ }^{3} \mathrm{http}: / /$ news.detik.com/berita/2884460/kisah-pilu-ijah-tki-asal-subang-ditusuk-majikan-dan-dibuang-keluar-rumah ${ }^{4} \mathrm{http}$ ://www.rumahdiahpitaloka.org/tki-asal-subang-pulang-tanpa-nyawa/

${ }^{5} \mathrm{http}: / /$ news.liputan6.com/read/2224452/pulang-penuh-luka-tki-asal-subang-meninggal-dunia
} 
Indonesia) di Desa Sindangsari Kecamatan Cikaum Kabupaten Subang ini ialah sebagai berikut: (1) meningkatkan pengetahuan kepada mantan TKI di Desa Sindangsari tentang peluang usaha cookies; (2) meningkatkan keterampilan dalam membuat cookies berbahan baku lokal bagi mantan TKI yang berada di Desa Sindangsari; (3) memberikan keterampilan pengelolaan usaha cookies berbahan baku lokal bagi mantan TKI yang berada di Desa Sindangsari. Setelah selesai kegiatan Pelatihan Produksi dan Usaha Cookies Berbahan Baku Lokal Sebagai Alteratif Usaha ini, manfaat yang dapat diperoleh yaitu: (1) meningkatnya pengetahuan mantan TKI tentang peluang usaha cookies; (2) meningkatnya keterampilan dalam membuat cookies berbahan baku lokal bagi mantan TKI; (3) meningkatnya keterampilan pengelolaan usaha cookies berbahan baku lokal bagi mantan TKI; dan (4) berpeluang dijadikan sebagai usaha bagi mantan TKI.

Khalayak sasaran yang strategis dalam kegiatan Pelatihan Produksi dan Usaha Cookies Berbahan Baku Lokal Sebagai Alteratif Usaha Bagi Mantan TKI (Tenaga Kerja Indonesia) di Desa Sindangsari Kecamatan Cikaum Kabupaten Subang yang berjumlah 20 orang mantan TKI yang bekerja di luar negeri.

Untuk memecahkan masalah belum adanya alternatif usaha bagi mantan TKI maka metode pendekatan yang dipilih adalah dalam bentuk pelatihan. Metode ini dipilih agar para mantan TKI memiliki keterampilan yang bisa diandalkan dan dapat membuat usaha cookies yang dapat diandalkan. Tahapan dan prosedur kerja yang akan dilaksanakan diuraikan sebagai berikut. Pertama, penyusunan konsep pelatihan untuk mengidentifikasi: (1) standar kompetensi, kompetensi dasar dan indikator hasil pelatihan; (2) materi pelatihan cookies; (3) alokasi waktu pelatihan yang dibutuhkan; (4) metode pelatihan yang akan dilakukan; dan (5) sumber, media dan alat pelatihan yang akan digunakan. Kedua, ujicoba untuk memperoleh formula yang tepat untuk dilatihkan kepada masyarakat sasaran dan prototype produk yang akan dihasilkan sekaligus sebagai contoh-contoh dalam proses pelatihan. Ketiga, penyusunan media dan hand out untuk mendapatkan: (1) media pembelajaran yang akan digunakan dalam bentuk power point, media nyata (produk), foto, dsb; dan (2) hand out materi pelatihan yang akan diberikan kepada peserta. Keempat, persiapan pelaksanaan yang untuk: (1) menyiapkan bahan dan alat pelatihan; (2) terkoordinasikan dengan pihak mitra untuk persiapan tempat, peserta dan hal teknis lain yang dibutuhkan untuk pelatihan; (3) penggandaan hand out; dan (4) persiapan transportasi dan distribusi logistik pelatihan. Keempat, pelaksanaan pelatihan untuk memastikan bahwa: (1) peserta pelatihan dapat mengetahui dan memahami cookies; dan (2) peserta pelatihan dapat membuat cookies. Kelima, evaluasi pelatihan untuk memperoleh informasi tentang kualitas proses dan hasil pelatihan. Kegiatan dilaksanakan mulai bulan Mei sampai dengan Agustus 2016 dengan biaya sebesar Rp. 10.000.000,- (sepuluh juta rupiah).

\section{PELAKSANAAN DAN HASIL KEGIATAN}

Pelaksanaan kegiatan pengabdian masyarakat dengan judul: "Pelatihan Produksi dan Usaha Cookies Berbahan Baku Lokal Sebagai Alteratif Usaha Bagi Mantan TKI (Tenaga Kerja Indonesia) di Desa Sindangsari Kecamatan Cikaum Kabupaten Subang" dilakukan dalam beberapa tahapan dari mulai persiapan, pelaksanaan sampai evaluasi hasil pelatihan. Setiap tahapan pelaksanaan kegiatan pelatiha diuraikan sebagai berikut.

\section{PENYUSUNAN KONSEP PELATIHAN}

Tahapan pertama yang dilakukan ialah penyusunan konsep pelatihan yang akan dilaksanakan. Hasil tahapan penyusunan konsep pelatihan sebagai berikut. Pertama, teridentifikasi standar kompetensi, kompetensi dasar dan indikator hasil pelatihan sebagai berikut: (1) standar kompetensi yang mencakup (a) memahami cookies, dan (b) membuat cookies berbahan baku lokal untuk meningkatkan pendapatan keluarga; (2) kompetensi dasar yang mencakup: (a) memahami klasifikasi kue; (b) memahami cookies, dan (c) membuat cookies; dan (3) indikator hasil pelatihan yang terdiri dari (a) peserta pelatihan dapat menjelaskan klasifikasi kue, (b) peserta pelatihan dapat menjelaskan cookeis, dan (c) peserta pelatihan dapat memproduksi cookies. 
Kedua, mengidentifikasi materi pelatihan yang dibutuhkan untuk disampaikan kepada peserta pelatihan yaitu: (a) pengenalan cookies, (b) alat dan bahan membuat cookies; dan (3) proses pembuatan cookies.

Ketiga mengidentifikasi alokasi waktu pelatihan yang dibutuhkan. Berdasarkan hasil analisis diketahui alokasi waktu yang dibutuhkan untuk melakukan pelatihan ini selama enam jam pelatihan, di mana setiap jam pelatihan terdiri dari 60 menit. Sehingga total waktu yang dibutuhkan selama 360 menit.

Keempat, mengidentifikasi metode pelatihan yang akan dilakukan. Berdasarkan hasil kajian, metode pelatihan yang tepat digunakan yaitu ceramah, tanya jawab, tutorial, dan praktik membuat cookies.

Kelima, mengidentifikasi sumber, media dan alat pelatihan yang akan digunakan. Berdasarkan hasil kajian, sumber belajar yang tepat digunakan ialah nara sumber yang ahli di bidang pembuatan cookies yaitu Mulyati, S.Pd., M.Si. Media pembelajaran yang digunakan ialah slide presentasi berupa powerpoint dan produk cookies (sampel). Alat pelatihan yang digunakan yaitu laptop, LCD Projector, alat dan bahan pembuatan cookies.

\section{UJI COBA}

Sebelum dilaksanakan pelatihan, terlebih dahulu perlu dilakukan ujicoba pembuatan cookies. Ujicoba dilakukan agar pada saat pelatihan tidak terjadi gagal produksi, serta dapat mengantisipasi segala kemungkinan yang terjadi selama proses pembuatan cookies. Ujicoba pembuatan juba bertujuan untuk mendapatkan sampel produk yang akan tunjukkan kepada peserta pelatihan. Selain itu, ujicoba juga digunakan sebagai bagian dari proses pembuatan media pembelajaran berupa foto untuk setiap tahapan pembuatan cookies. Kegiatan ujicoba dilakukan selama bulan Juli-Agustus 2016. Setelah cookies jadi, tahapan selanjutnya ialah perancangan dan pembuatan kemasan cookies. Untuk pembuatan langkah-langkah yang telah dilaksanakan diuraikan sebagai berikut. Kemasan yang digunakan ialah kemasan toples plastik, sehingga desain label juga menyesuaikan. Untuk penjualan produk cookies diperlukan kemasan yang menarik bagi konsumen. Maka dari itu dibuat desain dengan bentuk dan kombinasi warna yang menarik bagi konsumen. Gunakan desain label kemasan yang telah dicetak pada permen jelly antanan kemasan plastik dan jar. Seperti ditunjukkan dalam gambar di bawah ini.
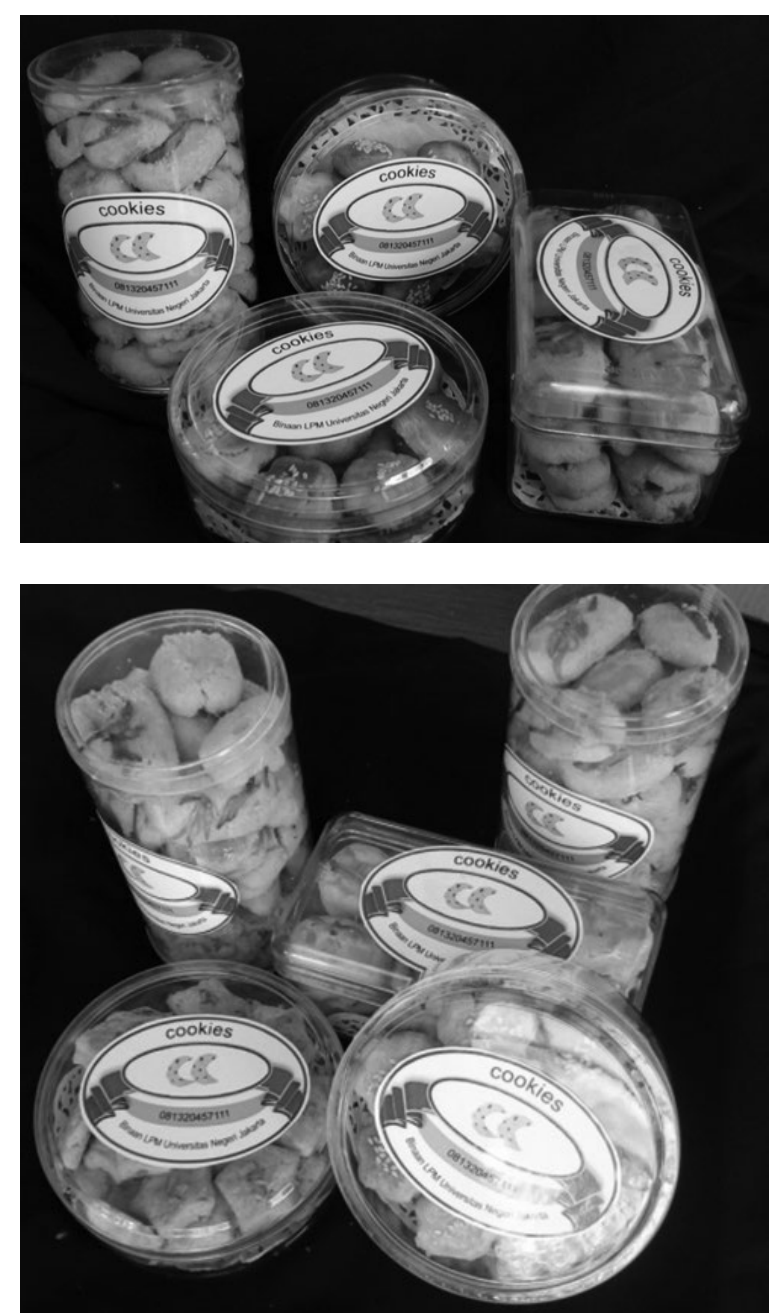

Gambar 1. Hasil Cookies

\section{PENYUSUNAN MEDIA DAN HAND OUT}

Untuk mendukung efektivitas kegiatan pelatihan pembuatan cookies, diperlukan media pembelajaran dan hand out yang akan dibagikan kepada peserta pelatihan. Media pembelajaran yang digunakan berupa slide power point, foto, produk permen jelly antanan, hand out untuk peserta pelatihan. Penyusunan media pembelajaran dan hand out dilakukan pada bulan Agustus 2016. 


\section{PERSIAPAN PELAKSANAAN}

Agar kegiatan pelatihan berjalan dengan lancar, terlebih dahulu perlu dilakukan persiapan yang baik. Kegiatan persiapan dilakukan pada bulan Juli dan awal Agustus 2016. Hal-hal yang dipersiapkan antara lain: (1) bahan dan alat pelatihan; (2) koordinasi dengan pihak mitra untuk persiapan tempat, peserta dan hal teknis lain yang dibutuhkan untuk pelatihan; (3) penggandaan hand out materi pelatihan; (4) persiapan transportasi, dan (5) distribusi logistik pelatihan.

\section{PELAKSANAAN PELATIHAN}

Pelaksanaan kegiatan pelatihan dilakukan pada tanggal 28 Agustus 2016 bertempat di Madrasah, Komplek Masjid AMinah Binti Wahab, Kampung Kajan Utara Desa Sindangsari Kecamatan Cikaum Kabupaten Subang. Pelatihan dimulai pada pukul 09.00 sampai dengan pukul 15.00 WIB. Acara pelatihan dimulai dengan sambutan pimpinan lembaga mitra, sambutan ketua tim pengabdian masyarakat (Tarma, S.Pd., M.Pd) dan dilanjutkan dengan materi (teori) serta praktik pembuatan cookies. Pelaksanaan kegiatan dihadiri oleh pimpinan lembaga mitra, coordinator peserta dan 22 orang peserta yang umumnya mantan TKI yang pernah bekerja di Taiwan, Malaysia, Abudhabi, Saudi Arabia, dan Singapura.

\section{EVALUASI PELATIHAN}

Untuk mengetahui dan meastikan bahwa kegiatan telah mencapai tujuan yang diharapkan maka diperlukan adanya evaluasi. Evaluasi dilakulan berdasarkan kinerja yang ditunjukkan oleh peserta pelatihan serta pandangan peserta pelatihan tentang proses pelatihan yang telah dilaksanakan. Secara umum diketahui bahwa peserta pelatihan telah menguasai materi pelatihan.

Berdasarkan pelaksanaan "Pelatihan Produksi dan Usaha Cookies Berbahan Baku Lokal Sebagai Alteratif Usaha Bagi Mantan TKI (Tenaga Kerja Indonesia) di Desa Sindangsari Kecamatan Cikaum Kabupaten Subang" yang telah dilak- sanakan pada tanggal 28 Agustus 2016, diperoleh hasil sebagai berikut: (1) peserta pelatihan dapat menjelaskan klasifikasi kue; (2) peserta pelatihan dapat menjelaskan kue kering; dan (3) peserta pelatihan dapat memproduksi cookies.

\section{KESIMPULAN DAN REKOMENDASI}

Setelah selesainya kegiatan pengabdian masyarakat berupa pelatihan pembuatan permen jelly antanan sebagai supplement untuk meningkatkan daya ingat bagi satri penghafal Al Quran di Pesantren Sabilia Citeureup Kabupaten Bogor, ada beberapa hal yang dapat disimpulkan, yaitu:

1. Kegiatan berjalan efektif dan efisien sesuai dengan rencana yang telah ditetapkan sebelumnya.

2. Setiap tahapan kegiatan dari mulai persiapan, pelaksanaan dan evaluasi berjalan sesuai rencana yang telah ditetapkan.

3. Peserta pelatihan dapat menguasai sepenuhnya materi pelatihan yang telah diajarkan dan dilatihkan.

4. Pimpinan lembaga mitra menanggapi positif pelaksanaan kegiatan pelatihan ini dan mengharapkan kegiatan pelatihan selanjutnya.

Berdasarkan proses yang dijalani selama kegiatan pengabdian masyarakat ini, ada beberapa hal yang perlu direkomendasikan, yaitu:

1. Bagi masyarakat sasaran (peserta), diharapkan dapat mendayagunakan dan memanfaatkan pengetahuan dan keterampilan dalam membuat cookies setelah kegiatan pelatihan selesai. Serta dapat melakukan proses produksi baik untuk memenuhi kebutuhan keluarga sendiri atau untuk dijual ke masyarakat luas.

2. Bagi LPM, diharapkan kegiatan pengabdian masyarakat terus dilaksanakan pada tahuntahun selanjutnya dengan biaya yang lebih besar agar lebih banyak manfaat yang dapat diberikan kepada masyarakat. 